\title{
NAVIGATING COMMUNITY-ENGAGD SCHOLARSHIP WITHIN NEOLIBERAL ACADEMIC INSTITUTIONS
}

\author{
By \\ Rebecca Pacheco, BA, University of Waterloo 2017 \\ BSW, University of Waterloo 2018
}

An MRP

Presented to Ryerson University

\author{
In partial fulfillment of the \\ Requirements for the degree of \\ Master of Social Work \\ in the program of \\ Social Work
}

Toronto, Ontario, Canada, 2019

(C) Rebecca Pacheco, 2019 


\begin{abstract}
AUTHOR'S DECLARATION
AUTHOR'S DECLARATION FOR ELECTRONIC SUBMISSION OF A MRP

I hereby declare that I am the sole author of this MRP. This is a true copy of the MRP, including any required final revisions.

I authorize Ryerson University to lend this MRP to other institutions or individuals for the purpose of scholarly research.

I further authorize Ryerson University to reproduce this MRP by photocopying or by other means, in total or in part, at the request of other institutions or individuals for the purpose of scholarly research.

I understand that my MRP may be made electronically available to the public.
\end{abstract}




\begin{abstract}
Navigating Community-Engaged Scholarship Within Neoliberal Academic Institutions Master of Social Work, 2019

Rebecca Pacheco

Program of Social Work, Ryerson University

The overall purpose of this research was to identify systemic conditions within academia that are preventing researchers from engaging in CES, and ultimately, influence change in university policies and procedures pertaining to community-based research. Using interpretive phenomenological inquiry, four community-engaged social work scholars were interviewed about their experience with participating in communityengaged research. The interviews explored the experiences of community-engaged scholarships within the current academic context, and how their work is valued, recognized and rewarded by their academic institution. It was found that the participants had a common understanding that community-engaged scholarship and its research outcomes remain largely undervalued by the majority of academia. The participants provided many of their own personal experiences while also pointing out restrictive policies and practices at their university. The implications of these trends are discussed and entry points for change in the academy are highlighted.
\end{abstract}




\section{ACKNOWLEDGMENTS}

There are so many people who deserve to be acknowledged for their influence on this work, as without them none of this would have been possible. To my MRP supervisor, Purnima George, I would like to thank you for your ongoing support and encouragement throughout this research process. Your dedication to your students and work is staggering. I also want to acknowledge my incredible family, and more specifically, my mom Enza and my dad Tony, who have shown me unconditional love and support over the last six years of my educational journey. They love and accept me for all that I am and have always encouraged me to follow my passions. And to my older brother Vinny, thank you for all the love and laughs - Ha! You're not the only master anymore! Lastly, to my chosen family, all of the incredible friends and sisters in my life, thank you for supporting me through all the highs and lows of this journey. You know who you are - and there is no way I would have done this without your love and support. You are incredible strong women and you inspire me everyday. 


\section{DEDICATION}

To all the participants in this study who generously donated their time and told their stories. May you continue to do the incredible work and research that you do and continue to be an incredible example for the next generation of researchers. 


\section{TABLE OF CONTENTS}

Chapter 1: Introduction 1

$\begin{array}{ll}\text { Chapter 2: Literature Review } & 6\end{array}$

Chapter 3: Theoretical Framework 16

$\begin{array}{ll}\text { Chapter 4: Methodology } & 20\end{array}$

Chapter 5: Major Findings 25

Chapter 6: Discussion and Implications 43

$\begin{array}{ll}\text { Chapter 7: Conclusion } & 48\end{array}$

Appendix A: Informed Consent

Appendix B: Recruitment Letter $\quad 52$

Appendix C: Interview Questions 53

References $\quad 54$ 


\section{CHAPTER 1. INTRODUCTION}

Over the past 15 years, the "public scholarship movement" (Matthews, 2005) has triggered a broader exploration and practice of community-engaged scholarship (CES) in academia (Franz, 2009). Academics are being implored to have greater accountability and relevance to their communities, particularly when it comes to research and public service (Barreno, Elliott, Madueke \& Sarny, 2013). However, despite this increasing trend, academics still experience obstacles to practicing a more holistic approach to scholarship (Franz, 2009). According to Franz (2009), "faculty are looking for practical ways to plan, implement and reflect on engaged scholarship," however, they are not able to find the necessary "entry and leverage points" within the current neoliberal structure of academic institutions" (p. 31). Academia is largely driven by a neoliberal agenda that is founded on a profit-oriented individualist narrative (Feldman \& Sandoval, 2018). In order to defend their credibility as an academic, researchers are having to disregard cultural and community knowledge to pursue traditionally rewarded and economically profitable forms of scholarship (Feldman \& Sandoval, 2018). The overall goal of my research is to identify the systemic conditions within academia that are preventing researchers from engaging in CES, and ultimately, influence change in university policies and procedures based on existing leverage points for change.

I have spent the last six years studying in post-secondary institutions and have gained considerable insights of how universities function as neoliberal institutions. In journeying through my education, I have read countless research articles, reports and reviews that have utilized various research outlooks, practices and theoretical frameworks. My interest and passion for research has continued to grow, and as a result, I 
have pursued various opportunities to lead and assist on a variety of research projects. Through these experiences, I have come to understand the importance of adopting holistic research practices and the potential harm that research can have when conducted unethically. I have done previous research on CES and utilized an exploratory lens in building a foundational understanding of this type of research. In furthering and building on this knowledge, this research project is going to utilize a more critical lens to understand how neoliberal institutions are impacting the practice of CES.

When envisioning my career as a social worker, I see research being a large component of my work. As such, it is incredibly important that I continue to develop my understanding of community-engaged research that is written through a social justice lens. Before beginning this project, it is important to recognize that although I am a student, I am also a researcher, and there is power and influence that is inherent in that title. Although I recognize the importance of CES for community members, I must also acknowledge that I have never been harmed by unethical research practices. Therefore, my research will not be based in or supplemented by my personal experience or history with harmful research practices. However, I will be contributing my prior knowledge on CES to this project and must remain aware of how this prior experience and knowledge may influence my current research (Preston \& Redgrift, 2017). In pursuing antioppressive research and utilizing interpretive phenomenology as my approach of inquiry, it is important to be transparent with my influence as the researcher and work towards promoting a co-construction of knowledge with research participants and myself (Preston \& Redgrift, 2017). 
According to Ochocka and Janzen (2014), when practiced authentically, CES is "seen as a catalyst for social innovation, for public policy improvement, for solving complex community issues and for promoting democracy in which local knowledge is valued in building local solutions" (p.18). By creating a reciprocal relationship, CES is mutually beneficial for both academic researchers and community partners. However, in order for CES to become common practice in academia, certain institutional and cultural norms need to be adjusted. This particular research project is important, as the first step in eliminating outdated structures and policies is to identify them and recognize how they reinforce and encourage traditional western academic practices. In identifying the cultural and institutional barriers that are discouraging the practice of CES at Canadian universities, the goal is to simultaneously uncover potential policies and structural supports, that when implemented, would value and reward community-engaged research as a legitimate and rigorous form of scholarship (Gelmon, Jordan \& Seifer, 2013).

Research is an integral component of social work, both as a practical discipline and a field of study. As such, if social work wants to evolve within an anti-oppressive framework, CES needs to become a more widely practiced form of research methodology. Anti-oppressive social work practice was developed in response to the social divisions and structural inequalities that are often present between clients and workers (Strier \& Binyamin, 2013). Similarly, these power dynamics and inequalities are often present between academics and community members during the process of knowledge production. CES is an alternative approach to research that counters the colonizing narrative of traditional academic research by recognizing community members as equal partners in knowledge production and mobilization (Minkler, 2005). In 
securing equitable participation by community members, CES strives to ensure that community stakeholders share equal control of the research agenda throughout every stage of the research process (Ochocka \& Janzen, 2014). The implications of shifting how knowledge is produced and shared are immense and transcend any one researcher, faculty or academic institution (Saltmarsh, Giles Jr., Ward \& Buglione, 2009). CES has the potential to impact how knowledge is organized, shared and understood and can have a tremendous impact on the understanding and application of authentic anti-oppressive practice.

The overall purpose of this research is to identify systemic conditions within academia that are preventing researchers from engaging in CES, and ultimately, influence change in university policies and procedures pertaining to community-based research. I have also identified specific objectives for my research that when achieved, will help in fulfilling my overall research purpose. These specific objectives are as follows:

1. Explore the research values of academics

2. Explore why academics perceive community-engaged scholarship to be valued in academia

3. Explore how academics perceive higher academic institutions to be influenced by neoliberal values

4. Explore how social work values influence academic research decisions

5. Explore academic recommendations in establishing community-engaged scholarship as a recognized legitimate research practice

In completing this research and speaking to academics involved in CES, my goal is to highlight entry points for change within the academic system. After reviewing the relevant literature, explaining my research methodology and presenting the resulting data, 
I will conclude by identifying tangible and clear policy and procedural changes that universities can make to encourage the practice of CES within their institutions. 


\section{CHAPTER 2. LITERATURE REVIEW}

This literature review will provide a substantive overview of the available literature on CES, including a comprehensive definition of CES, the benefits of CES and its perceived legitimacy, the importance of tenure and reward policies for CES and the presence of neoliberalism in academia. I will conclude this section by highlighting the gaps in the existing literature and how my research will help to fill these gaps.

\section{Defining Community-Engaged Scholarship}

Within the context of this research, I will be utilizing Cynthia Gordon da Cruz's (2018) definition of CES: "Community-engaged scholarship refers to mutually beneficial partnerships between universities and communities designed with the intention to collaboratively develop and apply knowledge to address consequential public issues" (p. 148). 'Community-engaged' refers to the partnership that forms between academic institutions and community partners, and involves active collaboration, dialogue and shared power and decision-making among all those involved (Hawkins, n.d.). This type of engagement describes the collaboration that takes place between community members and academics that aim to conduct research, evaluate social impacts and mobilize knowledge in order to address and solve an identified social problem (College of Social and Applied Human Sciences [CSAHS], 2011). The outcome of CES often goes beyond research and scholarship solely for academic purposes, and usually includes scholarship produced to inform and meet the needs of community members (Jordan, 2007).

CES is an effective way to democratize research practices and break down the monopolized claim on knowledge and truth that universities currently have (Van Katwyk \& Case, 2016). Academics who engage in this type of research actively recognize the 
shared expertise of community members and the value of knowledge and expertise that they have to offer (Van Katwyk \& Case, 2016). Traditional academia is based in the perception that academics need to engage with community members from a distance as the logical experts who perform academic tasks on the community, rather than in collaboration with them (Van Katwyk \& Case, 2016). According to Van Katwyk and Case (2016), this type of exclusion of community members can be described as a "disgust response" and serves to sustain the uneven power dynamics between academics and community members. These uneven power dynamics have created a division between academics who are considered the "knowledge producers" and community members who are considered the "knowledge consumers" (Saltmarsh, Hartley \& Clayton, 2009). CES aims to dismantle these power dynamics, and renew academia's relationship to community and its civic responsibility (Van Katwyk \& Case, 2016).

The generated products of CES are referred to as outcomes and are understood to demonstrate new knowledge as it is collected (Metzger \& Szekeres, 2010). The outcomes from any particular community-engaged project are going to depend on the needs of the community involved and the specific outlined goals of each collaboration. The outcomes of CES generally balance community priorities with academic requirements for knowledge generation, transmission and application (Calleson, Jordan \& Seifer, 2005). According to Calleson, Jordan \& Seifer (2005) there are three main products of CES that are able to achieve this balance: peer-reviewed articles, applied products and community dissemination products. Peer reviewed journals are the most traditionally accepted academic product and aim to communicate "field lessons learned and descriptions of innovative programs" through a documentation of research methods and findings 
(Calleson et al., 2005, p. 319). Applied products focus on the "immediate transfer of knowledge into application" and aim to strengthen the collaborative ties between academics and community members (Calleson et al., 2005, p. 320). Examples of applied products include innovative intervention programs, training materials, resource guides and policies at the community, provincial and national level (Calleson et al., 2005). Community members particularly value these products because they aim to improve the functioning and health of a community (Calleson et al., 2005). Community dissemination products include community forums, newspaper articles and presentations to community leaders and policy makers (Calleson et al., 2005). These products provide opportunities for reflexive analysis by both community members as well as academics (Calleson et al., 2005).

\section{Benefits of CES}

The benefits of practicing genuine CES are quite extensive, and extend to the researcher, the academic institution and community partners. Sharing power within academia is a revolutionary act, and is fundamental in building a democratic education system (Freeman, Gust \& Aloshen, 2009). When practiced authentically, CES can be beneficial for community partners and their community as a whole. CES has the potential to result in real and meaningful social change for community partners by providing new knowledge and insights into community concerns (Freeman, Gust \& Aloshen, 2009). According to Freeman, Gust and Aloshen (2009):

"The production of knowledge through community engagement, whether by communities or academic institutions, will help to promote social justice and social change for the common good, but the sharing of that knowledge will help us to determine the practices that will be most beneficial and strategic in serving the common good" (p. 99). 
Academics also benefit from engaging in genuine CES, as they gain access to knowledge and wisdom from community members that they otherwise would not have acquired (Freeman, Gust \& Aloshen, 2009). These meaningful partnerships and unique experiences have the potential to reveal new insights and perspectives on existing social issues facing a community. It is therefore increasingly important that academics receive the necessary recognition for this type of research, so they can continue to be recognized and incentivized to participate in CES (Freeman, Gust \& Aloshen, 2009).

\section{Perceived Legitimacy of CES}

CES has yet to be universally accepted as a legitimate form of academic research, and therefore, does not receive the same level of recognition and reward when compared to traditional research methods. Calleson and colleagues (2005) stated that untenured faculty members are more likely to be promoted if they get published articles in peerreviewed journals rather than when they engage in research practices and outcomes that are community-based. As a result, these faculty members are often reluctant to dedicate their time and research to community-based issues and research because it is considered "too professionally risky" (Calleson et al., 2005, p. 317). Academic culture places the highest value on individual in-depth, theory-based research that aims to expand knowledge within one specific field (Scott, 2007). According to Scott (2007), in this academic system, "the often more interdisciplinary, collaborative, and real-world applied character of engaged-community research, where a specific problem is the primary focus, is looked down upon or not considered when it comes to determining tenure and promotion" (p. 9). Universities have a monopoly on deciding what counts as legitimate research and knowledge, and have continued to reinforce their status and power by 
marginalizing other forms of knowledge production, like CES (Van Katwyk \& Case, 2016).

\section{Reforming Reward and Tenure Policies}

The available literature on CES emphasizes that in order for this work to become a more legitimately recognized form of research, academic institutions need to reform their reward policies to appropriately value this type of scholarship. According to Gordon da Cruz (2018), "CES is more likely to be practiced if university policies support the recognition and promotion of faculty undertaking this type of scholarship" (p. 159). Active steps must be taken to create and sustain an organizational structure that values CES on both an institutional and cultural level (Scott, 2007; Van Katwyk \& Case, 2016). Universities need to align their research goals with the goal of community engagement and integrate this into all aspects of their structure, policies and procedures (Scott, 2007). In order for this institutional change to occur, it is necessary to create a cultural change within academia in regards to how CES is perceived (Saltmarsh et al., 2009). There needs to be a shift in the values and beliefs that academics hold pertaining to their recognition of the importance of connecting institutions of higher education to their surrounding communities (Saltmarsh et al., 2009). Before institutional changes can be implemented, there needs to be widespread recognition within academic culture about the value and legitimacy of community-based research (Saltmarsh et al., 2009).

A study done by Kerry O’Meara (2005) found that academic institutions that “initiated formal reforms to encourage multiple forms of scholarship were significantly

more likely than their counterparts to report a higher percentage of tenure and promotion cases that emphasized their work in teaching and engagement scholarship" (p. 502). In 
this study, 729 Chief Academic Officers from across American universities filled out a survey regarding the impact of policy efforts in encouraging multiple forms of scholarship in faculty roles and rewards (O’Meara, 2005). The role of Chief Academic Officer includes: promoting ongoing faculty development, managing the scarce resources dedicated to faculty scholarship, working with committees to make changes to faculty evaluation criteria and processes, and evaluating promotion and tenure cases before they are sent to the university president (O’Meara, 2005). The results of the study indicated that institutions that made policy reforms had significantly different institutional and cultural environments pertaining to CES (O’Meara, 2005). These institutions had scholarship assessment criteria that were more conducive to a wider definition of scholarship, had a higher percentage of tenure and promotion cases that emphasized engagement scholarship and were more likely to report an increased congruence between faculty priorities and institutional missions (O’Meara, 2005). However, it is important to note that O'Meara (2005) recognizes that although there is an increase in tenure and promotion cases that highlight engagement scholarship at reform institutions, there were no significant differences in the success of these candidates when compared to traditional campuses.

\section{Neoliberalism in Academia}

The influence of neoliberalism on higher education is profound and carries implications that exceed beyond any one academic institution (Henesworth, 2017). Many scholars believe that the neoliberal influence on higher education is strategic and focused on dismantling academia as a public space that produces critical inquiry, exploration and self-reflection (Apple, 2006). Higher education presents both a threat and an opportunity 
for neoliberal thinkers because academia threatens to produce ideas that oppose neoliberalism, but can also be a space that reproduces their ideology (Henesworth, 2017). As a result, neoliberal thinkers aim to implement academic capitalism within educational spaces, to ensure that educational institutions no longer operate for the public good and to acquire critical knowledge, but rather, to operate as an 'academic capitalist knowledge/learning regime' (Slaughter \& Rhoades, 2004, p. 7). The implications of this neoliberal academic culture are particularly detrimental to schools committed to social justice and equity, most notably social work, because their curriculum, teaching methods, goals and research agendas contradict neoliberal beliefs (Preston \& Aslett, 2014).

According to Henry Giroux (2010), higher education as it currently stands practices bare pedagogy, which "is a political and social practice that mirrors the economic neo-Darwinism of neoliberalism" (p. 185). This pedagogy emphasizes marketdriven rationality and removes ethical considerations, compassion and moral responsibility as a priority (Giroux, 2010). Higher education is no longer committed to addressing social problems faced by communities; rather, they are being driven by corporate greed, values and power (Giroux, 2010). According to Giroux (2010):

"Bare pedagogy stripes education of its public values, critical contents and civic responsibilities as part of its broader goal of creating new subjects wedded to the logic of privatization, efficiency, flexibility, the accumulation of capital, and the destruction of the social state." (p. 185).

Rooted in this idea of a bare pedagogy, "academic capitalism" is now being used to describe university policies and practices that reflect neoliberal private sector values (Slaughter \& Rhoades, 2004). Knowledge is increasingly being seen as a commodity that only academics can produce and profit from (Slaughter \& Rhoades, 2004). Therefore, 
within this neoliberal academic system, there is no room for community involvement or the investment in community-engaged research that does not serve corporate interests.

\section{Limitations and Gaps}

One of the largest limitations of the existing knowledge on CES is that the discipline of social work has contributed very little to it. There are numerous disciplines that have contributed to the relevant literature on CES; however, social work is not one of those disciplines. Some of the disciplines that have contributed to this knowledge include public health, occupational therapy, critical sustainability education and cultural studies. It is particularly concerning that social work scholars have not done a considerable amount of research on this topic, as given their social justice framework, they should be actively engaging in CES. According to Preston and Aslett (2014), social work faculty should be working to deconstruct neoliberalism within academia and reestablishing the commitment of academic institutions to social justice and equity, which would include their chosen research practices. However, the literature does not provide any examples of social work scholars participating directly in community-engaged research, or doing any sort of research assessing the impacts or benefits of this methodology. According to George (2018), there are "few examples of schools of social work that have gone beyond their traditional realm into engaging in social change oriented activities by standing with their marginalized communities in resisting oppression and injustice" (p. 144). One of these "social change oriented activities" can include CES, as academic-community partnerships can create knowledge that results in meaningful social change.

Another limitation associated with the existing knowledge on CES is that it is extremely Americanized, meaning that most of the available research has been done 
within American institutions of higher education. According to Vuong and colleagues (2017), "In the US, there have been profound studies and guidelines that respond to questions relating to faculty perspectives on, and involvement in, community-engaged work" (p. 251). It seems that Canadian academics have largely been excluded in constructing this type of research, which has created a gap in knowledge. Although it is possible to assume that Canadian academic institutions have similar experiences and structures to American ones, one must remain cautious in generalizing these results to academic institutions in other countries. Concrete assumptions should not be made about the perspectives of academics, and therefore, these academics should be engaged in dialogue in order to acquire a better understanding of how neoliberal policies and structures actually translate to faculty experiences.

Much of the available literature on CES is written about faculty experiences within American academic institutions. According to Vuong and colleagues (2017), "Outside the US, most research on the topic [community-engaged scholarship] points to national contexts and institutional policies related to engaged work, but none specifically studies faculty attitudes" (p. 252). In response to the knowledge gap that this has created, I am going to be asking faculty about their experiences and perspectives within Canadian academic institutions. In conducting this research within a Canadian context, hopefully the results will indicate whether cultural and institutional norms of higher education differ from an American context.

In response to the lack of literature available written from the discipline of social work, my research will specifically involve the perspectives and experiences of academics from Canadian schools of social work. This decision was intentionally made 
to respond to the apparent gap in knowledge that is written through a social work lens. Additionally, it will be interesting to observe whether social work academics are taking active steps to deconstruct neoliberal structures and engage in equitable research practices. I am curious to determine whether the role and title of social worker impacts the research decisions that academics make.

Based on the available literature on CES, I believe my research will supplement it nicely and fill an existing gap. There needs to be a space created that engages directly with academics, specifically within a Canadian context, to get a better understanding of the current academic culture surrounding CES. These insights will be crucial in understanding where there are opportunities for positive change within institutions of higher education. The question guiding my research is: What are the systemic conditions within academia that are preventing researchers from engaging in CES and what changes need to be made to university policies and procedures pertaining to community-based research?

The available literature on CES effectively explores and highlights the benefits of CES and its perceived legitimacy, the importance of tenure and reward policies for CES and the foundational role of neoliberalism in academia. After identifying an existing gap in the literature, my research will create space to engage directly with Canadian social work academics to gain insights into the current academic policies and culture surrounding CES. In the next chapter, I will be presenting the theoretical frameworks that have informed my research design and execution. 


\section{CHAPTER 3. THEORETICAL FRAMEWORK}

Qualitative researchers often rely on a variety of theories or conceptual

frameworks in order to identify relevant concepts and maximize the contribution of their findings (Padgett, 2017). My research utilizes critical theory as a way to move beyond data reduction and description and into interpretation and advocacy (Padgett, 2017). This section will explain critical theory as it relates to my research methodology and goals.

\section{Critical Theory}

Much of the available literature on CES utilizes critical theory in grounding its research objectives and methodologies. My research is also going to be based in critical theory, as it is the most appropriate and relevant theoretical framework. Critical theory is based in six essential actions: examining historical and cultural contexts, considering power distribution, engaging in self-reflection, practicing non-judgmental inquiry, acknowledging values and realizing that from greater awareness comes action (Salas, Sen \& Segal, 2010). According to Salas, Sen and Segal (2010): "Critical theory provides a framework for understanding how the social order runs, what place and role each of us has within it, the effect the system has on us, and what we can do to change it" (p. 92). Critical thinking is also essential in this process, as while critical theory provides the relevant framework, critical thinking is the actual reflexive tool that culminates in social change (Salas, Sen \& Segal, 2010). Critical thinking involves asking the vital questions, gathering and analyzing the relevant information and recognizing the assumptions, implications and consequences of certain thought processes (Salas, Sen \& Segal, 2010). 


\section{Critical Qualitative Inquiry}

According to Charmaz (2017), critical inquiry is "embedded in a transformative paradigm that seeks to expose, oppose and redress forms of oppression, inequality and injustice" (p. 35). My research will utilize qualitative inquiry that is informed by critical theory in order to understand the lived experience of community-engaged academics that work within a neoliberal academic structure. Denzin (2017) believes that critical qualitative inquiry incorporates the necessary practices and values to interrogate and reimagine the neoliberal public sphere. When practiced authentically, critical qualitative inquiry places the voices of the oppressed at the center of the research and reveals opportunities for positive change (Denzin, 2017). In utilizing critical qualitative inquiry, it is important that I critically analyze and scrutinize my data, my research practices and myself throughout the research process (Charmaz, 2017). I must remain flexible to having to rework or alter my methodological strategies in reflection of my own discoveries along the way (Charmaz, 2017). In using this framework, I hope to gather a more in-depth understanding of how academics interpret and understand the structures they work within, and potential entry points for resistance (Denzin, 2017).

Critical qualitative inquiry is particularly relevant to this research, as this framework is based on many of the same values and research practices that CES is. Like CES, critical qualitative inquiry recognizes that traditional academic research relies too heavily on narrow evidence-based measures of quality for both academics and their research projects (Denzin, 2015). Academic standards of evaluation are understood to be too objective and based in positivist thought (Denzin, 2015). Alternatively, critical qualitative inquiry advocates that when measuring the quality of research and action, 
academia needs to adopt moral criteria that celebrate resistance, experimentation and empowerment (Denzin, 2015). This framework aligns well with CES, which recognizes that research with community members is not a linear process and the outcome of these collaborations are not always going to be academic journals, however, they should not be evaluated as inferior to traditional research outcomes.

\section{Critical Social Theory}

Related to critical theory, critical social theory aims to provoke meaningful critiques of existing systems and practices, and then stimulate the appropriate social activism (Agger, 2006). According to Agger (2006), "the aim of knowledge is

enlightenment and liberation, not the enhancement of personal professional credentials or the advancement of one's discipline" (p. 17). This theory recognizes that in order to meaningfully penetrate a research question, participants need to be substantially involved throughout the research process (Charmaz, 2017). In actively including community members in the research process, academics acclaim the value of subjectivity in the research process (Manias \& Street, 1999).

Critical theory has a particular relevance to my research, as the participants are not only academics, they are social workers as well. Social workers are mandated to pursue social justice goals in their practice by the code of ethics, and this would extend to their research practices as well (Mackinnon, 2009). From a critical social theory perspective, the social justice mandate of a social worker is inherently in conflict with the current neoliberal academic structure (Mackinnon, 2009). There is an undeniable tension between the research demands of academic institutions and the mandate of critical thinking and practice for social workers (MacKinnon, 2009). 
Critical theory was of significant importance in moving forward from data collection and analysis to identifying calls to action and advocating for change within academic institutions. Critical theory and its key concepts and tenets will be particularly woven throughout the discussion and conclusion sections of this paper as I move from analysis to action. 


\section{CHAPTER 4. METHODOLOGY}

This chapter will explain the methodology of interpretive phenomenological inquiry, including a description of this method and why I chose to use it for this research. This chapter will also include a description of my sampling procedure, participant recruitment, the data collection tool I utilized and how I analyzed all the data I collected.

\section{Approach of Inquiry}

In gathering my data, I conducted interpretive phenomenological inquiry in attempting to comprehend the lived experiences of participants, while also considering the context of the individual's specific context (Preston \& Redgrift, 2017). According to Preston and Redgrift (2017), "phenomenological inquiry is concerned with an individual's experience with a phenomenon through exploring the essence of experience" (p. 88). More specifically, I will be utilizing interpretive phenomenology, as opposed to descriptive phenomenology, in order to understand how the history and context of each individual participant has impacted their experience as an academic and a communityengaged scholar (Preston \& Redgrift, 2017). While descriptive phenomenology aims to understand the lived experience of an individual on a surface level, interpretive phenomenology attempts to understand how human reality is impacted by social, cultural and political factors (Preston \& Redgrift, 2017). According to critical social theory, it is these social, cultural and political factors, systems and practices that are then used to stimulate the appropriate social activism (Agger, 2006). I have structured my interview questions with this goal in mind, and framed my questions to elicit more in-depth answers about the academic histories of each participant. 


\section{Sampling}

This study utilized purposive sampling, as potential participants were contacted based on whether they met certain eligibility criteria required for this study (Bernard, 2000). According to Padgett (2017), purposive sampling is "a deliberate process of selecting respondents based on their ability to provide the needed information" (p.68). Inclusion criteria for this study were twofold. First participants needed to be a faculty member at an Ontario university, specifically within a school of social work. Second, participants needed to be currently engaging in or completed a community-engaged research project. I utilized Cynthia Gordon da Cruz's (2018) definition of CES: “community-engaged scholarship (CES) refers to mutually beneficial partnerships between universities and communities designed with the intention to collaboratively develop and apply knowledge to address consequential public issues" (p. 148). Academics who were engaging in genuine collaboration with communities to address particular social issues experienced by community members were deemed eligible to participate in this study. My decision to only include faculty members within schools of social work was purposeful, as I believe this will add an interesting layer of analysis to this research. The sample size for this study is four social work academics.

\section{Recruitment}

I generated a contact list by visiting the websites of various schools of social work within Ontario and collecting the contact information of professors that had relevant research interests. University websites generally provide faculty lists for each department, in addition to each person's research interests, publications and contact information. All of the information that I collected is public information, and is accessible to anyone. 
Contact information was collected for faculty members who listed community-based research, scholarship and practice as an interest of theirs. In total, 30 social work academics were contacted from 11 schools of social work within Ontario. Each person was sent an email with a recruitment letter with all the information about the study (see Appendix B).

\section{Data Collection}

Qualitative interviews were conducted with participants as the data collection method in this study. This particular type of research tool is commonly used in social research, as it effectively gathers in-depth information and experiential knowledge from research participants (Patton, 2002). As interviews were the only data collection method used in this research, only primary sources of information were utilized. These one-onone interviews were unstructured, as this is often an effective tool in moving gathered information from general topics to more specific insights (McCammon, n.d.). Prior to the interviews I developed an interview guide with relevant questions, however, there was flexibility in the sequencing of these questions and not all of them were necessarily used in each interview (Padgett, 2017). When conducting any form of phenomenology, Preston \& Redgrift (2017) "suggest there be very few pre-planned questions in advance of data collection, with additional questions based on the answers provided by participants, to focus the research on the lived experience of the participants" (p. 91). Based on their recommendations, I made an interview guide with neutral open-ended questions about CES that revealed the study's key domains, which are "classes of information from which a variety of questions could be asked, some prepared in advance and others elicited through probes" (Padgett, 2017, p.115). These interview guides 
ensured that while the interviews were minimally structured, they were not fully improvisational (Padgett, 2017).

Four interviews were conducted with academics, and each ranged from 60 to 90 minutes. Each interview was completed voluntarily and was audio recorded, with the permission of the interviewee, so that it could be transcribed and analyzed. Each interview took place at a different location and was chosen based on mutual convenience of the researcher and the participant. The interview was composed of eight main questions, some of these questions had additional probing questions that were designed to stimulate and deepen the conversation. (See Appendix C for the Interview Questions).

\section{Data Analysis}

Phenomenological analyses generally include synopses of each participants' experiences and a summary of major themes with relevant excerpts from the interviews (Padgett, 2017). The first step of the analysis process is termed horizontalization, which involves reading across the interviews repeatedly to identify important statements in the data and groups these into themes (Padgett, 2017). According to Moustakas (1994), textural description is attached to themes in order to highlight the participants' lived experience. The next step of analysis involved a structural description and a broader examination of the context of the participants' lived experience (Padgett, 2017). The final step of the analysis was to synthesize the meanings into essences (Padgett, 2017). According to Padgett (2017) "the essence is the condition or quality without which a thing would not be what it is" (p.159). This was done by using both textural and structural description to arrive at a blended understanding and depiction of the phenomenon (Moustakas, 1994). 


\section{Ethical considerations}

This research is intended to be of minimal risk to participants as every effort was made to keep participants anonymous and keep all of their identifying information private. There is however, some social risk involved in critiquing the neoliberal structure of the institution that participants are employed at. Participants may risk being isolated or ostracized as someone who speaks out against the status quo. Upholding strict confidentiality and preventing the identification of participants will mitigate these risks. Each participant was assigned pseudonyms for their name, research project and institution of employment, and only these pseudonyms will be used in any of the audio recordings, transcripts or notes. No direct identifiers were used in communications and publications about the research, and indirect identifying information will be associated with specific findings and direct quotations only with the explicit consent of the participant from which that quotation/finding is derived. There was no demographic information collected from the participants. Participants were also informed that they could withdraw from the study at any point without consequence and that all of their data would then be destroyed.

My research utilized interpretive phenomenological inquiry in order to understand the lived experience of participants and their understanding of CES within academia. The next chapter will present the results of this inquiry and highlight the central themes of participant interviews. 


\section{CHAPTER 5. MAJOR FINDINGS}

This chapter will discuss the findings from the four interviews conducted with participants. The findings that are included in this chapter were selected based on their relevance in answering the research question. The aim of this study is to identify systemic conditions within academia that are preventing researchers from engaging in CES, and ultimately, influence change in university policies and procedures pertaining to community-based research. In what follows, I discuss four main areas that occurred during each interview and break down these areas into themes.

\section{Profile of Participants}

Each participating academic is currently employed as a professor in a school of social work at an Ontario university. As a result, these findings are based on a range of academic experiences that vary based on the academic institution, the academic values of that institution and the leaders of each university. All four of the key informants are currently involved in or have been involved in various community-engaged scholarship projects. Each participant disclosed that they began their social work career in the field as a direct practitioner, either in a clinical or community organizing capacity. To ensure confidentiality of the participants, their names will not be used, and instead they will be referred to as Key Informant 1 (KI1), Key Informant 2 (KI2), Key Informant 3 (KI3) and Key Informant 4 (KI4).

Key Informant 1 has been involved with community-engaged research for over 20 years, primarily with disability rights organizations. They started in the field as a community organizer working on the ground with grassroots organizations, which has significantly impacted their research values and agenda. After joining the academy, KI1 
took a two-year break from academia because they felt they could not authentically engage with the community while working within the timelines and limitations of the current academic system. Upon returning to the university, KI1 had a new outlook on academia and understood their position to be in service to the community and would therefore provide the necessary platform, tools and resources to authentically engage and conduct important research with community.

Key Informant 2 is currently involved in numerous community-engaged research projects and is the chair of the research centre at their school of social work. They started their social work career in clinical practice surrounding those living in poverty, but increasingly realized that systems were failing to address the underlying issue of systemic poverty. They then became increasingly interested in advocacy work and developed a research orientation based in community work and building supports for community.

Key Informant 3 is an arts-based, community-based researcher who has participated in many community-engaged research projects. They started their social work career with community work, and pursued their $\mathrm{PhD}$ because they wanted to engage in research, with no initial intention of becoming an academic. In entering academia, KI3 made a personal commitment to only remain in academia as long as they loved it and engaged in the type of community work they believed in. There was one particular period when they considered leaving academia because of the clash between their research values and the traditional academic expectations. They have chosen to only remain in academic spaces that allow them to engage in authentic community-based work, and have become a vocal advocate for CES. 
Key Informant 4 worked as a frontline social worker for 20 years before entering academia. They have been involved in numerous community-engaged projects and have been invited to work on projects with many different communities. KI4 believes that all research should lead to social change and that research is not an end in itself, but has to be used for a larger purpose. Their research was instrumental in advocating for the opening of a women's shelter in a community that was lacking this necessary resource. KI4 recognizes that academics are also members of various communities, and that they should therefore approach research as if they are inside the groups they are researching.

\section{Major Findings}

In exploring the major findings of my research, four areas of discussion will be presented. Each area of discussion will then be further broken down into relevant themes. The four areas of discussion that will be presented are as follows: influence of social work practice and values on CES; values of academia; CES and impact on career; and recommendations to encourage CES.

\section{Influence of Social Work and its Values on CES}

The first major area of discussion pertains to the influence of social work on the participant's research and teachings. All four of the participants expressed that their background in social work has undoubtedly influenced their research values and their decision to participate in CES. The themes that will presented in this section are as follows: background in frontline social work and the influence of social work on teaching. 


\section{Close relationship of social work practice and CES}

There was a general understanding that the values, beliefs and skills that are essential for social work practice are also essential when participating in communityengaged research. In reflection of this, Key Informant 3 commented:

"And I do believe all of the relationship building that happens in community-based work, I think my social work practice, and my social work skills are what get activated there.” (KI3)

Key Informant 4 recognized that if they were approaching research from a background other than social work, their approach to research would likely look completely different. In this case, their social work education, values and fieldwork had a direct impact on the type of research they choose to engage in as an academic. Key Informant 4 commented:

"Yeah, absolutely. One hundred percent. I think if I was a psychologist and hired into a Department of Psychology I would have a completely different approach. As a social worker, I was trained in a structural social work school, so I wasn't prepared as a clinician. ... And so I was taught by people who were teaching me about social change, more so than they were about treating people. I think that orientation was very important for me. And as an academic, but I mean if I'm not doing social change still I'm not sure I would feel like I was doing anything valuable with my job.” (KI4)

Key Informant 1 spoke about the influence of their social work practice and community organizing background over their research values and practices. In this case, their experience on the ground with community members was instrumental in constructing their understanding of what research should achieve and who it should belong to. Key Informant 1 commented:

"Because I'm a social work academic and so not only am I a social work academic but I'm also an academic who comes from a community organizing background. So I see the importance of making sure that research feeds back into the community and feeds back into changes, and how we do intervention for example or how we establish policies or practices or models of practice." ..."And I want to go back to my earlier days, because, you know, I came to the field like so many other people I 
came to being a social work academic from the practice field. And so I brought with me my ideas about community and community engagement and all of that." (KI1)

\section{Bringing social work practice orientation into teaching}

Key Informant 1 also spoke about the importance their social work background in terms of how they choose to teach their courses. Their community organizing background and community-engaged research has directly impacted the content of their courses and the approach they choose to take in educating and training future social workers. They commented:

"Like I say as somebody who comes from a community organizing background. When I came into academia, it was, I was, you know, looking at my classes as though I was training future practitioners Yeah, of course we always do that, as social work academics. But for me it was so present in my mind. So when I teach a certain course without naming the courses. Like other people's teach it from a very theoretical perspective, I teach the theory but then I'll say - okay, this is not a sociology course, this is a social work course, so how do you apply that to practice situations. And so I feel that the impact was really direct. Not only did it lead me to that kind of work, community engaged research, but it also impacted how I teach.” (KI1)

Having a background in social work practices seems to permeate through everything that academics do, including their research projects. The values and ethics that are essential to practicing authentic, critical anti-oppressive social work easily transcend into the academic world, particularly when participating in community-based work.

\section{Values of Academia}

The second major area of discussion pertains to the values that are dominant within academia. These values directly impact the policies, structures and governing systems of academic institutions. The themes that will presented in this section are as

follows: valuing conventional research methodologies; restricting academic policies and 
culture; relationship between administrative leaders and CES; and positive shift in how CES is valued.

\section{Valuing conventional research methodologies}

All four participants expressed in some capacity that their community-engaged scholarship is not regarded as highly as traditional quantitative research. There remains a universal perception that community-based work lacks the necessary rigor and prestige to be recognized as legitimate academic research. All four participants expressed that the academy has implemented policies, structures and expectations that discourage the practice of CES. These policies have also created an academic culture that is based in a research hierarchy that places community-engaged work and scholars at the bottom. Key

Informant 1 commented:

"I think some universities are still stuck in the mentality of scientific research and what that means. Some places, especially places with big money, have not moved necessarily. So the first university I worked at was a top-tier university, a research university. But unfortunately, research was defined in a very narrow, narrow way. So I think that's partly it. It's like bucking against the tradition. And you're right, the institutional changes are not enough, cultural changes need to happen at the same time." (KI1)

Although traditional research practices have often been violent and dehumanizing of individuals and communities, these research methodologies are still widely understood as the superior data collection approach. Key Informant 4 commented:

"Qualitative is always sort of assumed to be less rigorous and you have to show people that it is as rigorous. But scientific and quantitative methods in traditional research can still lead to social ill no matter how rigorous. And my research won't. And I can guarantee that." (KI4) 
There seems to be general consensus amongst the participants that academia continues to value conventional quantitative research methodologies over other approaches, particularly community-engaged research.

\section{Restrictive academic policies and culture}

Academic policies and expectations were not created with CES in mind, and as a result, many of these policies actively hinder and discourage the practice of authentic community-engaged research. University policies and expectations have not been adequately changed to accommodate CES, and this is having a tremendous impact on community-engaged academics. One particular challenge community-based researchers experience pertains to traditional academic timelines that are rigid and limited. Key

Informant 2 recognized this challenge with the comment:

"There's this constant pressure for faculty to kind of engage in more sort of traditional Western research. Community-based organizations or community-based research has some challenges for faculty. We have to be ready to give up some control, we have to allow the community to have much more say about the kind of research that we do, and choice of research questions and those kinds of things as well. Working with a community-based organization and having to deal with advisory committees, it's time consuming. You can't just sort of go in and collect your data and go out and do your own analysis. It involves umpteen meetings and changing sort of timelines. So I think that a lot of faculty find this kind of research really challenging." (KI 2)

Key Informant 3 shared similar insights around university timelines:

"I think the tenure track is also, the policies and expectations around what needs to be accomplished within six years, I think that, that conflicts with what needs to happen in a legitimate, but also a community-based project that has integrity." ... "And the university's timeline is so rigid, and so fast-paced, and relentless. And so even put, you know, oftentimes giving space to community-based project feels like you're breaking all the rules of an academic setting. Which actually gives me pleasure" (KI 3) 
Key Informant 2 shared their disappointment that a MSW research course they were co-teaching that was steeped in community-based research practices had recently been changed from mandatory to an elective. KI2 saw this course as invaluable to the community, as students were split into small groups and tasked with working with community-based organizations on various research projects. Every year that the course was run 10-12 community-based research projects were completed. There was no exchange of money for completion of this research, and KI2 was involved at every stage to ensure that the research was of a high quality. Despite the undeniable benefit to both the students and the communities, this course is no longer seen as important enough to remain as a mandatory course within that particular school of social work. KI2 expressed their concern that students are not going to recognize the importance of this course and that it is going to struggle to meet the minimum registration numbers. Key Informant 2 commented:

"So what we used to be kind of like a full credit required course for all MSW students is now going to become an elective. So I don't know how well that's going to work if anybody or any student is going to sign up for it. And I don't really know, because I'm retiring after this year. So July $1^{\text {st }}$ is my last official day. And so I at this point, I won't be involved in helping to develop this new research course elective." (KI2)

Participants spoke about many other university policies that impact their ability to engage in CES. Although one might not make the initial connection between these policies and CES, participants provided detailed insights into the range of policies that impact community-based work. For example, Key Informant 3 spoke about the university policies surrounding honorariums and how current policies restrict their ability to properly compensate community partners. Key Informant 3 commented: 
"So it's all its relationship building is our, you know, community-based work, right. And so a lot of times, with relationship building, you're thinking about concepts like reciprocity. Okay, so I work with youth. And a lot of the youth that I work with end up becoming co-researchers, participants that need to be thanked in one way or another with honorariums, with gift cards, whatever. So now, if I want to give somebody an honorarium, they have to go on to the university's payroll. So for me to give somebody $\$ 100$, for helping me with something, they have to give me their social insurance number. Social insurance number, a date of birth, they have to give me their email address, and their mailing address. And they have to sign a statement saying, I know that this is taxable, and I will be declaring this on my taxes. And they have to sign that statement. And then once I provide all that to the university, then the university contacts them. ... And so it completely impedes the kind of relationship building that community-based research could be. A lot of my research is also with and within indigenous communities. So it means that I seek out guidance from Elders. So I had to do this with a couple of Elders, and I just could not stand. How, like, I'm so embarrassed, I was horrified. ... I just think gift giving is not only an issue with Elders. Like all of our gift giving has to be uncontaminated by administrative demands and bureaucracy. ... So I think that that's another great example of a policy that completely interferes with the work of community-based research." (KI3)

Key Informant 4 talks about their experience in pursuing tenure and the tension that exists between university expectations and honouring community partners when choosing the first author of the publication. Key Informant 4 commented:

"So when I do research, in a social identity community with them, I don't like to have my name as the first author on the publication. I might have done the research and I might have written the work, but by sheer relationship and honouring of that relationship, I would prefer to put the people I work with first in the publication. But for tenure, you need to have articles published with your name as first author, because in traditional quantification of tenure that means that you were in the lead. And it's the questioning of the lead that I want to do. You know, so if I can demonstrate that I did all that research, I did all that work, I did the writing, but I'm putting somebody else's name first because their community led the research, I did the research, but didn't lead it." (KI4)

Key Informant 3 spoke about the change their university made regarding the obligation that professors have to engage in teaching, research and service to the 
community. Whereas there used to be an even $33 \%$ split between these three elements, this has changed to an obligation of $40 \%$ research, $40 \%$ teaching and only $20 \%$ service. This change has made it harder for them to engage in their community-based work and represents the under-valuing of this type of work in terms of taking up academic time. Key Informant 3 commented:

"Now, since then, the academic institution where I work, they have changed. So it's now $40 \%$ of your work has to be teaching, $40 \%$ has to be research, and $20 \%$ is service. So I think even by that shift, it's making it more difficult to do community-based work. Because community based work can't only be defined as research, it has to be, service has to become part of it right? As you start to build relationships with the agencies, you're going to be helping serve meals, or you're going to be distributing stuff, or you're going to be licking envelopes, or you're going to be doing whatever in the name of relationship building. That isn't technically a research activity. But now it has to be done. It can't also now anymore be accommodated by that $33 \%$ formula. Right. So that shifted. So in a way that's a really important piece, or, you know, piece of evidence of how the post-secondary institution is making it more difficult to do communitybased work, right." (KI3)

The participants were able to identify a variety of concrete examples of policies and university structures that are preventing or discouraging authentic CES. These policies reflect the value system present within academia which places community-based work at the bottom of the research hierarchy.

However, it is important to note that the key informants did recognize that they have experienced some positive changes over their career regarding how CES is perceived and valued in academia. There is more recognition that CES is valuable work for both the academy and its community partners. Although this is certainly not a universal shift in academia, it is important to recognize the positive changes that have happened. Key Informant 1 commented: 
"I think, so I've seen a change. I've seen a shift, let's call it that. Because part of what I've done as an academic is, I actually sit on adjudication committees and for the big funders and the big grants, and I've seen a change in the sense that at one point it used to be we were a minority in the sense of everybody else is doing different kinds of research, you know, quote unquote scientific research and we're doing community-based research or community-engaged research. And that was like you really have to justify why that was a legitimate form of research. I don't feel it's the same anymore, I feel that there's been a shift. I've sat around the table with people who are adjudicating grants for example, and some of the questions that come up are - Yeah, great study but what are they going to give back to the community? Or, wonderful research but this researcher looks like they're just parachuting into a community, doing their study and then leaving. So there's more of a critical perspective. I'm not going to say its shared by everybody, some people still think that traditional research is the only valid or legitimate source of knowledge. But a lot more. We're seeing that. We're seeing it, not just in the people I'm talking about, in individuals, but we're also seeing it in institutional type of requirements." (KI 1)

Key Informant 4 shared similar sentiments:

"I think in my department it's very valued, I think other social work researchers know that this is best practice. That you go forward with community and you solve problems and you do social change." ... "And I mean obviously they know that community-engaged work is messier, and it's more complicated and it's more time consuming. And so I think they respect that even though the projects may be small, the work behind moving those projects along is like community organizing, so I think it's very valued." (KI 4)

It is important to recognize the positive shifts that have begun in some academic institutions and the conditions that are necessary to facilitate these shifts in order to begin to replicate these changes and patterns across all of academia

\section{Recognition of CES by academic leaders}

A common theme discussed by the participants was the importance of the administrative leaders in creating an academic environment that either encourages or discourages CES. Administrative leaders, including the directors, principals and deans, have a direct impact on the policies and academic culture that impact the occurrence of 
community-engaged research. Key Informant 3 commented on their experience with administrative leaders:

"And so what I have dealt with for about six years now are directors who did not get or support my community-based work. And not only just my direct directors, I had a dean who told me that, for example, Humanities 101, the free university course, from the beginning I was told this will not help you get tenure. And if you put too much time into it, it will actually interfere with you getting tenure. Another dean, an academic dean, so like our [college] dean, not just within the department. Many times he told me, first of all, you need to do solo authorship. Well community-based research, it would actually be wrong to do solo authoring. Because that means I'm taking ownership of knowledge, that is actually that is not mine take ownership of." (KI3)

Key Informant 3 also discussed the changes they have experienced in their work because of the change in administrative leaders in their career.

"I have seen the change. And I think part of it has to do with who the leadership is. And so I think in the school social work, I think my directors valued the work. I don't think they completely understood the work, or at least I didn't feel like I was being completely understood. In terms of, I think that they were more thinking - I have a faculty member who may not get her tenure. And so they were concerned about my professional progress. And they saw my community work as getting in the way of it. So until maybe they were being really practical and saying - These are academic expectations, and you're operating in a way that goes against those expectations. So that was from my direct leaders. As it went up. I had, you know, one academic dean, who told me my journals weren't cutting the cake. And I felt very much that he really felt like I was inadequate as a scholar. Yeah, that's when I almost left the position, because I thought, I'm not loving this at all. Yeah. And like that was a really close call." ... "And then also, we had a principal who totally found it unworthy the work that I was doing. But now, we have an academic dean and I feel very valued by him. And we have a president, and I feel very valued by her and, and not as [Name of Key Informant 3], but as the work that I'm doing. I think that they are happy to have diverse approaches and diverse scholarship. And so they see my as a diversity then they walk on. So I'm really happy about that." (KI3)

The administrative leaders of a university play a pivotal role in shaping the academic policies and culture of their institution. They play a large part in deciding the values of an 
institution, and therefore, whether or not the university will take active steps in encouraging CES.

\section{CES and Impact on Career}

All of the participants expressed in some capacity that their involvement in CES has negatively impacted their career. In varying degrees, participants shared their experiences with CES and how their community-engaged research has either delayed their tenure application, resulted in an academic break or pigeon holed their academic portfolio. The themes that will presented in this section are as follows: delayed tenure/ impact on tenure and restricting research portfolio.

\section{Delayed tenure}

Key Informant 3 spoke in length about their experience of not being seen as "tenurable" because of their community-engaged research. They shared that their application was actually delayed because it was not seen as strong enough to find success in traditional academia. Key Informant 3 commented:

"And so when I first applied for tenure, I was actually asked to reapply in a year. So I wasn't actually turned down. I was just told your package will look stronger, if you - so we don't want to put this package forward." ... "But it worked against me, this community-based work, not because of my abilities as a scholar, but because academic immersed assessments were being placed on community-based activities. And there was a clash." ... "I do believe that my tenure application got put off by a year. Because - so that's a price I think I paid for not doing traditional, you know, nonengaged research. And that threw me off. Right. Yeah. It was, it was humiliating, actually." (KI3)

Key Informant 1 spoke about a two year break they took from academia because they felt their community-engaged research could not authentically exist within traditional academia. The isolation and discouragement they felt because of their CES had an undeniable negative impact on their career. Key Informant 1 commented: 
"It was well you're an academic now, so I don't understand why you're spending time in the community. Well, that was un-understandable to me, to the point where I actually thought seriously about leaving academia. And that is what happened. So I left for two years. Went back to the community because I was like, you know I can't do both at same time." ... "Community engaged scholarship is a thing. It's scholarship but it's community engaged. And so absolutely I did have those discouragements, to the point where it did impact my career" ... "It was a negative break it was a - the two cannot coexist. My heart is in the community. I can't be here anymore. It's very sad, It's devastating. It's an end of a career or so you felt at the time. But I had to overcome that and what helped me overcome that and gain the confidence was my connections with the community. That's really the solid footing that I had." (KI1)

Taking this type of break from your career is undoubtedly discouraging and can be potentially devastating in the competitive world of academia that values and demands constant outputs.

\section{Misrepresentation of research contributions}

Key Informant 4 expressed their frustration in getting pigeon holed as a scholar in a particular area even though it was not their area of scholarship. It is not uncommon to become known for participating in a certain type of research, even after completing only one project about a certain topic or with a certain community. This can be limiting for an academic in terms of the projects and communities they are able to take on and enter.

Key Informant 4 commented:

"I think everybody faces this as an academic or a researcher you get sort of pigeon holed. So people will say - Oh [Key Informant 4 name] does homelessness research. No I don't, no I don't. I did a project. I did community based stuff, that's all. Like, I don't care what it is or isn't because by the same token, you could say I do HIV research, because I did a project for and AIDS service organization. I don't do HIV research. So to sort of say that I'm a researcher of a subject area is difficult for me.

Obviously I have areas of competence and I wouldn't take on a community project in an area where I didn't understand anything about it. But, but I'm not a mental health researcher, or a homelessness researcher, I'm a community-based engaged researcher. So, if someone has a project they need someone to do, they could call me." (KI4) 
It can be limiting for a scholar to be known for only one research area, particularly for a community-engaged scholar, as it can become harder to build up trust and enter different communities.

\section{Recommendations to Encourage CES}

All four participants shared the changes they believe need to made to the university mandates, missions and policies in order to encourage and appropriately value CES. These recommended changes are diverse and would require changes to various levels of individual universities and academia as a whole. The themes that will presented in this section are as follows: professional development dollars; knowledge mobilization practices; and researcher vulnerability.

\section{Flexibility in utilizing professional development funds}

One recommended policy change made by two participants is to the restrictions surrounding how professors can spend professional development dollars. The restrictions placed on professional development dollars need to be loosened in order to allow academics to spend this money on appropriate honourariums and relationship building activities. Key Informant 3 commented:

"So thinking about how do we identify professional? And how do we make sure that our policies accommodate a broad definition of what professional is right? What would be some of the things that a professional development dollar would support? That feeds into community-based responses, right? What kind of relationship building activities would professional development dollars support? So I think that that's a really important change. And I identify it only because I'm seeing it starting to happen in my institution. But I know that it's super unusual. So that would be one change that I would suggest." (KI3)

Key Informant 4 shared similar sentiments with the comment: 
"How do we compensate community-based people in our scholarship? So, if I want to bring in guest speakers or co-teach or create a course together, like partner on course authorship. There's no money for that. Because they're not employees of the university, or you have a grant or something to do so. So even to have a public speaker in a classroom, the faculty has to take the money out of their own pocket or their own professional development allowance. Which is fine, but we don't have a big budget for that. So giving somebody $\$ 50$ for making their way to campus, you know, spending a night away from their own life, you know, like all the work that goes into that. And you give them like a $\$ 50$ coffee card, like that's not okay. So the idea of maybe like building in program funds for community engagement." (KI4)

Academics need to be trusted to spend their professional development dollars in ways that they believe to be most appropriate. Trust and relationship building with community partners is a fundamental component of CES, and it is essential that academics have the proper funding to appropriately facilitate this collaboration. Valuing CES based outcomes as highly ranked scholarly work

Key Informant 3 and 4 also spoke about changes that need to happen surrounding knowledge mobilization practices in order to recognize the alternative research products that often result from CES. Academia currently has a narrowly defined idea of knowledge mobilization, with publications in top tier journals being the most highly valued academic output. The outputs of CES are not commonly publications in top tier journals, and therefore, are not valued on the same level as other research methodologies. Key Informant 3 urged for the recognition of alternate ways of knowledge mobilization:

"I think, that knowledge mobilization, how knowledge mobilization gets defined, I think that there should be expectations that go, like really hard expectations that sort of indicate that publishing is an adequate activity. It's not a bad activity, but it's an inadequate activity. ... And so also shifting how we define impact, how we define important activities around knowledge mobilization, I think innovation should somehow be measured." (KI3)

Key Informant 4 shared similar sentiments with the comment: 
"I think for me there's those two things and this might be culture, but it also, I mean, might be a matter of policy but it's that idea of valuing academic output that might not look like publication. So like that idea of the photo gallery in the gallery exhibit, and like those things need to be sort of valued as much as the publication. Understanding the second author could be a valued position versus a tenure bait. I guess that's what we call it. But I think for me, it's one of the things that's very practical that you could focus on as a recommendation." (KI4)

Until academia recognizes and rewards alternate ways of knowledge mobilization, CES will continue to be placed at the bottom of the research hierarchy. There needs to be a fundamental shift in how academia perceives the purpose of research and its outputs.

\section{Redefining criteria for evaluating research}

Key Informant 3 spoke about "researcher vulnerability" and the importance of finding a way to make this a requirement when conducting research. When evaluating a researcher and their work, it is imperative to understand how they made themselves vulnerable and reciprocal in their research relationships, especially with community partners. No longer can researchers be evaluated on how well they show "expertise" on a subject, rather, they should be evaluated on how they demonstrate authentic vulnerability.

They commented:

"A really huge change that I think would be amazing, but I think is quite a ways down is that researchers, I think researcher vulnerability should somehow become a requirement. And what I mean by that is, right now all of our expectations and policies, they really allow for researchers to remain invulnerable, and uninvolved. So somehow, I'd like to see an expectation where researchers have to speak to personal transformation, or they have to indicate how they have reciprocated [and demonstrated] vulnerability in their projects, somehow." (KI3)

All of the participants provided valuable recommended changes they believe need to be made to academia in order to encourage CES. These recommendations are based on their first-hand experience within academia and the limitations and barriers they have 
encountered. As a result, these recommendations needs to be weighted heavily and seriously considered by higher level decision makers at every academic institution.

This chapter presented the four key areas that appeared in the interviews conducted with the four participants. In the next chapter, using my theoretical framework I will discuss the findings and explore the implications of these findings for academia and the occurrence of CES. In addition, the next chapter will end with recommendations for academic institutions to implement in order to encourage CES at their university. These recommendations will be directly based on these findings and the analysis of these results. 


\section{CHAPTER 6. DISCUSSION AND IMPLICATIONS}

Using critical theory, this chapter will discuss the findings of this research and explore the implications of these findings for academia and CES. The chapter will end by outlining four recommendations that if implemented would encourage the practice of CES more widely in academia.

The key informants had a common understanding that while CES and its outcomes are important for both academics and community partners, it remains largely undervalued by the majority of academia. There remains a wide perception that community-based research lacks the necessary rigor to be recognized and valued as legitimate academic research. This perception has been further legitimized with the implementation of policies, structures and expectations that discourage the practice of CES. There is a clear research hierarchy that places community-engaged work and scholars at the bottom.

These findings align with the available literature that highlights the dominance of neoliberal values and practices within academia. Based in neoliberal values, academia is no longer committed to addressing social problems faced by communities; rather, they are driven by corporate greed, values and power (Giroux, 2010). The literature emphasizes that academia is trying to dismantle itself as a public space, and is implementing policies surrounding commercialization and privatization in order to become a major part of the economy (Apple, 2011). CES does not have the same perceived economic value when compared to traditional quantitative research, which is likely a large reason that in an increasingly privatized education system, it is understood to be a less valuable use of time and resources. Key Informant 2 recognized that CES has 
much longer timelines than traditional positivist research because it requires giving up control, building trust and participating in countless consultation meetings. CES has a longer turnaround time for producing outcomes and publications, and therefore, is understood to be less economically valuable. Within a neoliberal and capitalist education system, producing less economically to the university equates to being undervalued and overlooked.

The key informants spoke to an increasing trend of higher education no longer being understood to be public institutions that exists to serve the larger community. As education moves towards privatization and neoliberal practices, it becomes implicated in the reproduction and contestation of relations of dominance and subordination of particular groups and types of research methodologies (Apple, 2011). There seems to be a growing separation between universities and the communities that surround them. This is the concept that Giroux (2010) described as "bare pedagogy," which is stripping education of its public values, critical contents and civic responsibilities in order to pursue the logic of privatization, efficiency, the accumulation of capital and the destruction of the social system (p.185).

There is a diminishing recognition of academics needing to be in service to their community, as this professional obligation continues to shrink. Key Informant 3 pointed out that when they started their academic career there was an even 33\% split between their obligation to engage in research, teaching and service. However, their service obligation has been cut down to $20 \%$, further isolating the university and academics from the community. Dedicated community-engaged academics are still participating in this community work, however, they are having to do this work in addition to their mandated 
responsibilities from the university. CES and community service is not understood to be valuable enough to equally exist within the basic requirements of an academic.

It is quite alarming to know that all four of the participants believe that their community-engaged research has negatively impacted their career in some capacity. If CES continues to go unrecognized and be undervalued, this type of research will continue to decline, or the academics that participate in this research will continue to be overlooked (Saltmarsh et al., 2009). Policy formation and institutional reward policies for faculty are a characteristic of the relationship between academia and the community (Saltmarsh et al., 2009). Therefore, current policies and reward guidelines that undervalue community-based work reflect the disconnect that is present between academia and the larger community.

All four of the participants recognized that their background in social work has influenced their research and teaching as an academic. There seemed to be a relationship between the values, beliefs and skills that are necessary in critical social work and the decision to participate in CES as opposed to traditional positivist research. Key Informant 4 recognized that their social work education, values and fieldwork actually had a direct impact on the type of research they choose to engage in. It seems that having a background in social work practices permeates through everything that academics do. In the case of these participants, their identity of social worker and academic were not independent or unrelated roles. Rather, their identity and background as a social worker had a significant impact on their identity as an academic and researcher. 


\section{Implications for CES and the Academy}

Before CES can be widely practiced in academic institutions, there needs to be a universal understanding that universities are public institutions that are deeply connected to the social contexts in which they exist (Apple, 2011). There needs to be a fundamental shift in the value systems that guide education, and a drastic move away from neoliberal values and practices. Education needs to be understood to be part of society that contains a key set of social and personal relations (Apple, 2011). As such, the education system and academics have a responsibility to their community and to challenge, rather than reproducing, the dominance of neoliberal and capitalist practices. Based on their responsibility, the mandate of academics to engage in community service needs to be reverted to a $33 \%$ split between research, teaching and service. This way academics will be able to participate in community-based work as part of their mandated job, rather than as something they choose to participate in off the side of their desk.

In order for CES to become a common practice in academia there needs to be fundamental shift in the understanding surrounding the purpose of research and how it is supposed to be used. Research needs to be understood as a catalyst and tool for social change. Research should not be completed as an end in itself, rather it needs to be a means in achieving a larger goal. Associated with this is recognizing the value in research outcomes and outputs that are not scholarly articles in top tier journals. The outputs of CES are vastly diverse and should not be held to the evaluation standards of traditional positivist research. Research outcomes and outputs need to be recognized as a tool for a larger purpose, and need to be used as such. Articles that remain unused on library shelves or online databases provide no continued value to the university or the larger 
community. Alternative knowledge mobilization practices of CES need to be appropriately recognized and valued for the purpose they serve in communities.

Academic structures and policies need to embed the values of CES within the institutional rewards policies that define the academic roles of teaching, scholarship and service. Academics need to be properly recognized and rewarded for their communityengaged work, particularly when it comes to applying to tenure. Community-engaged work cannot be relegated to an academic's teaching or service roles, it has to be recognized as part of the faculty's scholarship and research role (Saltmarsh et al., 2009). Community-engaged projects and outcomes must be weighed and considered equal to traditional positivist research when it comes to promotion and tenure guidelines. Community-engaged work must be recognized as legitimate scholarly research in order for it to be rewarded and valued as such.

It is important that CES is embedded in mandatory curriculum to ensure that students are taught about community-engaged research. Research courses that focus on community-based practices need to be recognized as valuable to any student's education, regardless of whether they are going to be pursuing research or academia as a career. The values and ethics that are necessary to participate in CES are applicable to many other careers and professions. These types of research courses must be mandatory for all students in order to impact the next generation of researchers and academics.

This chapter has further explored and analyzed the findings of this research through the lens of critical theory. Four recommendations were also made that if implemented would create the necessary cultural and institutional changes to encourage and value CES. 


\section{CHAPTER 7. CONCLUSION}

The aim of my research was to identify systemic conditions within academia that prevent researchers from engaging in CES. In identifying these systemic conditions, my ultimate goal would be for my research to be used to influence change in university policies and procedures that pertain to community-engaged research.

Four academics were generous enough to share their insights and experiences with CES within the current academic climate. Their vulnerability and trust in me to properly share their thoughts and feelings was essential in the success of this research project. My hope is that their authentic and vulnerable portrayals can be used to establish meaningful and necessary changes to academic culture and policies.

The findings of my research confirm that neoliberal values and practices remain dominant throughout all realms of academia. There are incredible academics doing CES, however, academic culture and policies are not at all conducive to community-engaged work. There needs to be substantial changes made to the current academic structures and institutions in order to properly value, encourage and recognize CES.

Based on the implications drawn from the findings and the changes I believe academia can make to encourage CES, my goal is to highlight entry points for change within the academic system. Academia is approaching a pivotal moment where it must decide whether it wants to continue to separate itself as a privatized elitist system, or to repair it connections with community and reconfirm itself as a public system. I hope that my research can be used to argue for the latter, and can provide tangible changes that can be made to encourage community-university connections and community-engaged work. 
There were limitations to this study that are important to point out. Although the participants were kept anonymous and all identifying information was excluded from this paper, there was no way to guarantee that participants would not be identified by the readers. As a result, the participants shared that they had to filter some of their answers out of fear that their remarks would get traced back to them and they would face consequences from their institutions of employments. This is a limitation of this study, as I feel that some of respondents were not able to always speak their truth out of fear of backlash from their university. This is a continued struggle that researchers have with their participants, to try and create a safe space to share their thoughts and opinions openly, while also minimizing any risk of participating in the research.

Although I only interviewed four key informants, which is a rather small number of participants, I actually believe this was a strength of my study. I was able to sit down and really connect with each participant on an individual level. I was also able to analyze and reflect on the data with more time and attention because there were only four transcripts to go through. I believe the data I collected is rich and can truly be used to create change within academia.

I visualize a number of possible areas for further research on CES. For example, research needs to be completed to build a concrete understanding of how certain reforms and changes are to be practically implemented within the current academic system in order to meaningfully establish CES as a common research methodology. It would be valuable to understand how these changes are best applied and what successful examples already exist that can be used. Another line of research that might be interesting to conduct would explore the attitudes of academics that do not participate in CES and who 
do not see the value in this type of research. This information would be helpful in further outlining the current academic context that CES advocates are working against and specific beliefs and attitudes that need to be addressed.

While my journey in completing this journal was not always smooth, it has been incredibly fulfilling and rewarding to see the final product come together. I am immensely proud of what I have produced, and am hopeful that this can be used to advocate for much needed change and reform within the academic system. This is just the beginning of my research journey, and I am eager and excited to see where it takes me. 


\section{APPENDIX A: INFORMED CONSENT FORM}

\section{Ryerson University Consent Agreement}

You are being invited to participate in a research study. Please read this consent form so that you understand what your participation will involve. Before you consent to participate, please ask any questions to be sure you understand what your participation will involve. [TCPS 2 Article 3.2(a)]

TITLE OF THE STUDY: "Navigating Community-Engaged Scholarship within Neoliberal Academic Institutions"

INVESTIGATORS: This research study is being conducted by Rebecca Pacheco and supervised by Purnima George, from the School of Social Work at Ryerson University.

If you have any questions or concerns about the research, please feel free to contact Rebecca Pacheco; rebecca.pacheco@,ryerson.ca or Purnima George; p3george@ryerson.ca

\section{PURPOSE OF THE STUDY: [TCPS 2 Article 3.2(b)]}

The purpose of this study is to explore how neoliberal structures within higher academic institutions are preventing academics from conducting genuine community-engaged scholarship (CES). This work will utilize a critical lens in analyzing the neoliberal culture present in Ontario universities, and how this has impacted community engagement in research practices.

This study will involve "Key Informant" (KI) interviews with 2-3 faculty members involved in community-engaged scholarship at schools of social work within Ontario universities.

The results of this research will be used in the completion of the researcher's Masters of Social Work as part of their Major Research Paper.

WHAT PARTICIPATION MEANS: If you volunteer to participate in this study, you will be asked to do the following things:

Research Participation:

- Participate in a one-time interview that will last approximately 45-60 minutes

- The location of the interview will be selected based on the mutual convenience of you as the participant, and myself as the researcher

- Phone interviews will be an option depending on distance Interview Content:

- Major research questions:

- What is your perceived value of community-engaged scholarship within an individual, community and institutional context? 
- How do you perceive community-engaged scholarship to be valued within academia?

- How do you understand academia to be a neoliberal institution?

- How has your decision to enter the discipline of social work impacted your research choices?

- What recommendations would you make to promote CES within academia? Research availability:

- Research findings and the final report will be made available to you in the Fall of 2019. I will contact you via email to inquire as to whether you would like a final copy of the report sent to you electronically.

POTENTIAL BENEFITS: [TCPS 2 Article 3.2(c)]

You will derive no direct benefits from your involvement in the project, beyond some potential satisfaction in knowing that your insights may help to highlight how the neoliberal structure of higher academics is discouraging the practice of communityengaged scholarship.

I cannot guarantee, however, that you will receive any benefits from participating in this study.

This research builds on and contributes to the understanding of higher academia as a neoliberal culture that discourages community-engaged scholarship and civic participation on the part of the university. This research is expected to help Ontario universities recognize how their institutional and cultural environments are oppressive and are preventing genuine collaboration with communities. In identifying these institutional shortcomings, administrators and policy makers will hopefully be pushed to move away from these neoliberal structures of higher education and create an environment that legitimizes and rewards community-engaged scholarship.

\section{WHAT ARE THE POTENTIAL RISKS TO YOU AS A PARTICIPANT: [TCPS 2 Article 3.2(c)] \\ There are minimal risks anticipated for your participation in this study. There is some social risk involved in critiquing the neoliberal structure of the institution that you are employed at. You may risk being isolated and ostracized as someone who speaks out against the status quo.}

There will be steps taken to mitigate these risks. Confidentiality will be strictly upheld in this study, and your name, research projects and institution of employment will be given pseudonyms. Your participation, including specific elements of your interviews, can be withdrawn from the study at any time prior to completion. You will be informed of the potential of these risks prior to beginning the interview and will be informed that you may skip any interview question, either temporarily or permanently. Direct quotations included in the report will not include any information that would enable a reader to identify the source without explicit written consent.

\section{CONFIDENTIALITY:}


We will protect your confidentiality and any other individuals named in the interviews by (1) storing the data in a secure, password-protected electronic file that can be accessed only by the Principal Investigator, (2) replacing your name and academic institution on documents with pseudonyms for the purposes of data analysis and in any public documentation, (3) storing the master sheet of names with their corresponding pseudonyms in the password-protected file, and (4) only identifying the source of quotations or ideas reported in research documents with your specific consent after vetting the text in question.

Due to the nature of this research you may want the opportunity to be named for the potential recognition as a community-engaged scholar. You will have the opportunity, therefore, to consent to being named as an individual or to have your academic institution or research project explicitly mentioned in the thesis. Please note that those who accept this offer will not have the confidentiality protections that would be provided to those who decide to remain anonymous.

With your permission, the interviews will be audio-recorded. Only the primary researcher will have access to the raw and transcribed recordings. You have the right to access and review the recordings and their corresponding transcripts at any time. Notes and recordings will be kept until the completion and approval of the MRP by the supervisor and second reader. All data will then be shredded and/or deleted. Notes and recordings of the interviews will be available to and used only by the primary researcher, and will not be played or made available to the public or anyone outside of the researcher.

VOLUNTARY PARTICIPATION AND WITHDRAWAL: [TCPS 2 Article 3.2(d)] Participation in this study is completely voluntary. You can choose whether to be in this study or not. If any question makes you uncomfortable, you can skip that question. If you choose to stop participating, you may also choose to not have your data included in the study. Your choice of whether or not to participate will not influence your future relations with Ryerson University or the investigator involved in the research.

QUESTIONS ABOUT THE STUDY: If you have any questions about the research now, please ask. If you have questions later about the research, you may contact: Rebecca Pacheco; rebecca.pacheco@ryerson.ca or Purnima George; p3george@ryerson.ca

This study has been reviewed by the Ryerson University Research Ethics Board. If you have questions regarding your rights as a participant in this study, please contact:

Research Ethics Board c/o Office of the Vice President, Research and Innovation Ryerson University 350 Victoria Street

Toronto, ON M5B 2K3

416-979-5042

rebchair@ryerson.ca 


\section{CONFIRMATION OF AGREEMENT:}

By signing this consent form, you are not waiving your legal rights or releasing the investigator(s) or involved institution(s) from their ethical, legal or professional responsibilities.

I have read and I understand the above information about a study being conducted by Rebecca Pacheco under the supervision of Dr. Purnima George of the School of Social Work at Ryerson University. I have had the opportunity to ask questions related to this study and to receive satisfactory answers to my questions.

- I am aware that I have the option of not allowing my interview to be audio recorded.

- I am also aware that excerpts from the interview may be included in publications to come from this research, with the understanding that the quotations will be anonymous.

- I was informed that I may withdraw my consent at any time without penalty by advising the researcher.

With full knowledge of all foregoing, I agree, of my own free will, to participate in this study.

$\square$ YES $\square$ NO

I agree to the use of anonymous quotations in any publication that comes of this research.

$\square$ YES $\square$ NO

I agree to be named in the final copy of the thesis. (Please note that by agreeing to be named, you will not have the level of confidentiality protection that you would have if you remained anonymous)

$\square$ YES $\square$ NO

I agree for my research project to be named in the final copy of the thesis. (Please note that by agreeing to have your project named, you will not have the level of confidentiality protection that you would have if your project remained unnamed)

$\square$ YES $\square$ NO

I agree to have my interview audio recorded. $\quad \square$ YES $\square$ NO

Participant Name: (Please print)

Signature:

Date 


\section{APPENDIX B: Recruitment Letter}

Project Title: $\quad$ "Navigating Community-Engaged Scholarship within Neoliberal Academic Institutions"

Researcher: $\quad$ Rebecca Pacheco; rebecca.pacheco@ryerson.ca

Faculty Advisor: Purnima George, PhD, School of Social Work (416-979-5000 ext. 7146); p3george@ryerson.ca

Dear [Insert name],

My name is Rebecca Pacheco. I am a student at Ryerson University in the School of Social Work. I am contacting you to see if you might be interested in participating in a research study.

This research is being done as part of my Masters project and my supervisor's name is Purnima George. The focus of the research is to explore if neoliberal structures within higher academic institutions are preventing academics from conducting genuine community-engaged scholarship.

In the context of this research, community-engaged scholarship will be understood using Cynthia Gordon da Cruz's definition: "community-engaged scholarship (CES) refers to mutually beneficial partnerships between universities and communities designed with the intention to collaboratively develop and apply knowledge to address consequential public issues" (2018, p. 148).

To participate you need to be a faculty member at an institution of higher education in the school of social work within Ontario that participates in community-engaged scholarship.

If you agree to volunteer, you will be asked to participate in a one-time interview that will last approximately 60-90 minutes. The location of the interview will be selected on the mutual convenience of you as the participant, and myself as the researcher.

Participation in this study is voluntary. You have every right not to participate, to refuse to answer specific interview questions, or to withdraw from the study at any time without penalty. Please note that there are no direct risks or benefits expected for participants.

This research [REB file number 2019-015] has been approved by the Ryerson University Research Ethics Board

If you are interested in more information about the study or would like to volunteer, please reach out to me by replying to this email. Additionally, if you know of someone who might be eligible and willing to participate in this study, please forward them this email or reply to this email with their contact information.

Thank you for your time and consideration.

Sincerely, Rebecca Pacheco 


\section{APPENDIX C: Interview Questions}

Project Title: "Navigating Community-Engaged Scholarship within Neoliberal Academic Institutions"

Researcher: $\quad$ Rebecca Pacheco; rebecca.pacheco@ryerson.ca

Faculty Advisor: Purnima George, PhD, School of Social Work (416-979-5000 ext. 7146); p3george@ ryerson.ca

\section{Interview Questions}

[Key informants will include faculty members from schools of social work from Ontario universities that currently or previously have participated in community-engaged scholarship (CES). They will be asked about how neoliberal structures within higher academic institutions are impacting their ability to conduct CES]

What is your perceived value of community-engaged scholarship within an individual, community and institutional context?

1) What research projects are you currently involved in, or have been involved in, that would be considered community-engaged scholarship?

- How long have you been involved in community-engaged research?

2) Why is engaging in community-engaged scholarship a priority for you as an academic? Why do you choose to participate in this type of research opposed to more traditionally accepted forms of scholarship?

- What do you see as the benefits to community partners or the community in general?

- What do you see as the benefits to the university?

How do you perceive community-engaged scholarship to be valued within academia?

3) How do you feel your community-engaged work is valued when compared to traditionally accepted forms of research? 
How do you understand academia to be a neoliberal institution?

4) Related to policies and institutional structures at your university, what challenges or barriers do you encounter that discourage CES?

- How do these policies directly impact your work? (Probe for an example if not clear)

5) Have you experienced any personal or professional backlash because of your participation in CES?

- How have you addressed these personal or professional challenges?

How has your decision to enter the discipline of social work impacted your research choices?

6) Do you believe your decision to become a social worker has impacted your research interests and your decision to participate in CES?

- Do you believe academics in other disciplines are as likely to participate in CES?

What recommendations would you make to promote CES within academia?

7) What do you think universities need to start doing to better encouraged CES within their institution?

- What institutional changes need to happen?

- What cultural changes need to happen?

8) Is there anything else that we have not touched on that you think is worth noting or discussing? 


\section{References}

Agger, B. (2006). Critical social theories: An introduction. UK: Oxford University Press. Apple, M. (2011). Democratic education in neoliberal and neoconservative times. International Studies in Sociology of Education, 21(1), 21-31.

Apple, M. (2006). Understanding and interrupting neoliberalism and neoconservatism in education. Pedagogies, 1(1), 6-21.

Barreno, L., Elliott, P., Madueke, I. \& Sarny, D. (2013). Community engaged scholarship and faculty assessment: A review of Canadian practices. University of Regina. Received from: http://engagedscholarship.ca/wpcontent/uploads/2014/10/Faculty-Assesment-Paper1.pdf

Bernard, H. (2000). Social research methods: qualitative and quantitative. Thousand Oaks, CA: Sage Publications.

Bloom, B., \& Crabtree, B. (2006). The qualitative research interview. Department of Family Medicine, 40(4), 314-321. doi:10.1111/j.1365-2929.2006.02418.x/full

Calleson, D., Jordan, C., \& Seifer, S. (2005). Community-engaged scholarship: Is faculty work in communities a true academic enterprise? Academic Medicine, 80(4), $317-321$.

College of Social \& Applied Human Sciences. (2011). Template for the development of assessment criteria for community engaged scholarship. Guelph, ON: Community Engaged Scholarship Institute. Retrieved from http://www.cesinstitute.ca/s ites/default/files/Template\%20for\%20the\%20dev elopment $\% 20$ of $\% 20$ assessment $\% 20$ criteria\%20for\%20CES.pdf 
Feldman, Z., \& Sandoval, M (2018). Metric power and the academic self: neoliberalism, knowledge and resistance in the British University. Triple C: Communication, Capitalism, Critique - Journal for a Global Sustainable Information Society, 16, 214-233.

Franz, N. (2009). A holistic model of engaged scholarship: Telling the story across higher education's missions. Journal of Higher Education Outreach and Engagement, $13,31-50$.

Freeman, E., Gust, S., \& Aloshen, D. (2009). Why faculty promotion and tenure matters to community partners. Metropolitan Universities Journal 20(2), 87-103.

Gelmon, S., Jordan, C., \& Seifer, S. (2013). Community-engaged scholarship in the academy: An action agenda. Change: The Magazine of Higher Learning, 45, 5866.

George, P. (2018). Moving beyond education to addressing injustice: Critical engagement of College of Social Work with eviction and deportation of pavement dwellers in Mumbai. In P. George, G. Balakrishnan, V. Anand and F. Chaze (Eds). Community practices in India: Lessons from the grassroots, pp.144 -154. UK: Cambridge Scholars Publishing.

Giroux, H. (2010). Bare pedagogy and the scourge of neoliberalism: Rethinking higher education as a democratic public sphere. The Educational Forum, 74, 184-196.

Gordon da Cruz, C. (2018). Community-engaged scholarship: towards a shared understanding of practice. The Review of Higher Education, 41(2), 147-167. 
Hanesworth, C. (2017). Neoliberal influences on American higher education and the consequences for social work programmes. Critical and Radical Social Work, 5(1), 41-57.

Hawkins, L. (n.d.). Defining our Terms: Community engagement and knowledge mobilization. Guelph, ON: Institute for Community Engaged Scholarship. Retrieved from http://www.cesinstitute.ca/sites/default/files/Survey\%20on\%20F aculty\%20Comm unity\%20Engagement\%20-\%20Results_0.pdf

Jordan, C. (Eds.). (2007). University of Minnesota promotion and tenure committee resource packet: Preparing to review the community-engaged scholar in the social and physical sciences. Guelph, ON: Community Engaged Scholarship Institute. Retrieved from http://www.cesinstitute.ca/sites/default/files/\%20 University\%20of\%20Minnesota\%20P\%20and\%20T\%20Committee\%20Resourc e\%20Packet_0.pdf

Mackinnon, S. (2009). Social work intellectuals in the twenty-first century: Critical social theory, Critical Social Work and Public Engagement. Social Work Education, 28(5), 512-527.

Manias, E. \& Street, A. (1999). Possibilities for critical social theory and Foucault's work: a toolbox approach. Nursing Inquiry, 7(1), 50-60.

Matthews, D. (2005). Preface to Engaging campus and community: The practice of public scholarship in the state and land-grant university system, by Peters, S.J., Jordan, N.R., Adamek, M., \& Alter, T. Dayton, OH: Kettering Foundation Press. 
McCammon, B. (n.d.) Semi-structured interviews. Design Research Techniques.

Retrieved from http://designresearchtechniques.com/casestudies/

Minkler, M. (2005). Community-based research partnerships: Challenges and opportunities. Journal of Urban Health: Bulletin of the New York Academy of Medicine, 82, 3-13.

Moustakas, C. (1994). Phenomenological research methods. Thousand Oaks, CA: Sage Publications.

Ochocka, J., \& Janzen, R. (2014). Breathing life into theory: Illustrations of communitybased research: Hallmarks, functions and phases. Gateways: International Journal of Community Research and Engagement, 7, 18-33.

O’Meara, K. (2005). Encouraging multiple forms of scholarship in faculty reward systems: Does it make a difference? Research in Higher Education, 46(5), 479-510.

Padgett, D. (2017). Qualitative methods in social work research, $3^{\text {rd }}$ edition. Thousand Oaks, CA: Sage Publications.

Patton, M. Q. (2002). Qualitative research and evaluation methods. Thousand Oaks, CA: Sage Publications.

Preston, S. \& Aslett, J. (2014). Resisting neoliberalism from within the academy: Subversion through an activist pedagogy. Social Work Education, 33(4), 502-518.

Salas, L., Sen, S. \& Segal, E. (2010). Critical theory: Pathway from dichotomous to integrated social work practice. Families in Society: The Journal of Contemporary Social Service, 91(1), 91-96.

Saltmarsh, J., Hartley, M., \& Clayton, P. (2009). Democratic engagement white paper. Boston, MA: New England Resource Center for Higher Education. Retrieved 
from https://futureofengagement.files.wordpress.com/2009/02/democraticengagement-white-paper-2_13_09.pdf

Slaughter, S. \& Rhoades, G. (2004). Academic capitalism and the new economy: Market, state and higher education. Baltimore: JHU Press.

Strier, R., \& Binyamin, S. (2014). Introducing anti-oppressive social work practices in public services: Rhetoric to practice. British Journal of Social Work, 44, 20952112

Van Katwyk, K. \& Case, R. (2016). From suspicion to accommodation to structural transformation: Enhanced scholarship through enhanced community-university relations. Engaged Scholar Journal, 2(2), 25-43.

Vuong T., Hoyt, L., Rowe, A., \& Carrier, C. (2017) Faculty perspectives on rewards and incentives for community-engaged work. International Journal of Community Research and Engagement, 10, 249-264. 